\title{
Oscillatory behaviour during the partial oxidation of methane over cobalt wires and foils
}

\author{
Xunli Zhang*, Colleen S.-M. Lee, D. Michael P. Mingos ${ }^{1}$, David O. Hayward \\ Department of Chemistry, Imperial College of Science, Technology and Medicine, South Kensington, London SW7 2AY, UK
}

Received 4 November 2002; received in revised form 12 February 2003; accepted 12 February 2003

\begin{abstract}
The oscillatory behaviour over cobalt wire and foil catalysts was examined at atmospheric pressure under various reaction temperatures and argon/methane/oxygen feed gas compositions for the partial oxidation of methane. Rough and porous oxide layers on the catalyst surface were confirmed by scanning electron microscopy (SEM) and X-ray diffraction (XRD) techniques. The results obtained from the experimental studies indicated that the oscillatory behaviour exhibited during methane oxidation was related to the behaviour of the catalyst surface switching back and forth from the reduced state to the oxidised state. The reduction of the oxide layer followed by the almost immediate re-oxidation of the metal can be accounted for only if the oxide layer formed by oxidation is different from the oxide layer existing during reduction.
\end{abstract}

(C) 2003 Elsevier Science B.V. All rights reserved.

Keywords: Methane partial oxidation; Oscillation; Cobalt wire catalyst; Cobalt foil catalyst

\section{Introduction}

The partial oxidation of methane under catalytic conditions has increasingly received attention recently, mainly because of its potential use as a commercial source of syngas $\left(\mathrm{CO}+\mathrm{H}_{2}\right)$, while the steam reforming of methane, which is the dominant industrial process currently in use, suffers from high energy requirements, a higher $\mathrm{H}_{2} / \mathrm{CO}$ ratio than is required and poor selectivity for $\mathrm{CO}[1,2]$. The complexity of the reaction pathways involved in the catalytic oxidation of methane can result in oscil-

\footnotetext{
* Corresponding author. Present address: Department of Chemistry, The University of Hull, Hull HU6 7RX, UK.

Tel.: +44-1482-466369; fax: +44-1482-466416.

E-mail address: x.zhang@hull.ac.uk (X. Zhang).

${ }^{1}$ Present address: St. Edmund Hall, The University of Oxford, Oxford OX1 4AR, UK.
}

latory kinetics under certain circumstances. Such oscillations have been observed over palladium catalysts [3-6], and supported nickel catalysts [7-9]. There has also been a report of oscillations occurring over an $\mathrm{Nd}_{2} \mathrm{O}_{3} / \mathrm{MgO}$ catalyst containing an exposed chromel-alumel thermocouple [10]. However, the oscillatory mechanism is still not understood in detail, although it is generally accepted that the cyclic oxidation/reduction process is responsible for the oscillation $[8,9]$.

Our previous studies showed that chromel-alumel thermocouples, when no other catalyst was present, can act as effective catalysts for the methane/oxygen reaction oscillating at temperatures between 700 and $740{ }^{\circ} \mathrm{C}$, where nickel was found to be the active ingredient [11]. In this paper we report the first observation of oscillations over cobalt wire/foil metal catalysts when an argon/methane/oxygen mixture was passed and the further investigations into the 
oscillatory reaction kinetics. The oscillations were studied in terms of reactant and product concentrations as well as temperatures. By varying the reaction conditions, the regime of oscillatory behaviour has been revealed, which could lead to new insights into the reaction mechanisms. This work was, in fact, initiated after oscillations were observed in the reactant and product composition together with reaction temperature when a mixture of methane and oxygen was passed through a quartz tube containing only quartz wool and a chromel-alumel thermocouple. It was evident that the thermocouple wires were catalysing the reaction and this led to the investigation into the catalytic activity of a range of transition metal wires and foils.

\section{Experimental}

The catalytic reaction was carried out under atmospheric pressure by flowing an argon/methane/oxygen mixture over a nickel wire coil or foil, located centrally in a $10 \mathrm{~mm}$ i.d. quartz tubular reactor that was heated by a tubular furnace. The effluent gas from the reactor outlet after reaction was analysed with a 16-channel quadrupole mass spectrometer (QMS-200D, European Spectrometry Systems), which was connected to the atmospheric pressure part of the system via a set of differentially pumped needle valves. The mass spectrometry data, together with the thermocouple measurements, were recorded by a real-time, computerised data acquisition system (Sensorlab V.5, Fisons Instruments, Vacuum Generators Quadrupoles). To prevent condensation of water vapour produced during the reaction, the needle valves and connecting tabulations were heated to about $200^{\circ} \mathrm{C}$. Mass flow controllers (ASM model AFC-260) were used to mix the feed gases in known proportions prior to reaction. The gas flows used were in a range of $30: 29: 1-30: 22.5: 7.5 \mathrm{ml} \mathrm{min}^{-1}$ of the argon/methane/oxygen mixtures.

A modified thermocouple was designed and made in the laboratory for the experiment, based on the law of intermediate metals for thermocouples [12], which states that if one or both of the junctions of a thermocouple are opened, and one or more metals are interposed, the resultant electromotive force (emf) is not altered provided that all the new junctions are at the same temperature as the original junction between which they are positioned. The thermocouple consisted of a length of chromel wire and a length of alumel with a cobalt coil or foil interposed to join the ends of the two thermocouple wires. This modified thermocouple was used to measure the temperature while the interposed cobalt wire or foil worked as a catalyst. The system temperature without reaction in the reactor was measured by means of stopping one of the reactant gases while keeping the power supply to the furnace unchanged.

Both the cobalt wire (diameter: $0.25 \mathrm{~mm}, 99.95 \%$ purity, length: $10 \mathrm{~cm}$ ) and the cobalt foil $(3.5 \mathrm{~mm} \times$ $7.5 \mathrm{~mm}, 99.9 \%$ purity, thickness: $0.025 \mathrm{~mm}$ ) were purchased from Goodfellow. It was spot-welded with $0.5 \mathrm{~mm}$ diameter chromel and alumel wires, which were also obtained from Goodfellow. The compositions of the chromel and alumel wires were $90 \%$ $\mathrm{Ni} / 10 \% \mathrm{Cr}$ and $95 \% \mathrm{Ni} / 5 \%(\mathrm{Al}+\mathrm{Mn}+\mathrm{Si})$, respectively. Methane (purity 99.0\%) and oxygen (purity 99.6\%) were purchased from Aldrich. Argon (purified) was supplied by BOC Gas.

The structure and the composition of the catalyst surface were determined by the techniques of scanning electron microscopy (SEM) and X-ray diffraction (XRD) using, respectively, a JSM-T200 scanning electron microscope and a PW1710 X-ray diffractometer (Phillips Electronic Instruments) with $\mathrm{Cu} \mathrm{K} \alpha$ radiation of wavelength $1.540 \AA$.

\section{Results and discussion}

\subsection{Surface analysis}

Cobalt foil/wire catalysts have been analysed after undergoing reaction by both X-ray diffraction and scanning electron microscopy analysis techniques. It was found, from the X-ray diffraction pattern of cobalt foil catalyst after undergoing reaction (seen in Fig. 1), that both cobalt $\left(2 \theta=52.0,55.2\right.$ and $\left.58.5^{\circ}\right)$ and oxide phases were present. It was also observed that two types of cobalt oxides $\mathrm{CoO}(2 \theta=36.8,42.8$ and $\left.61.5^{\circ}\right)$ and $\mathrm{Co}_{3} \mathrm{O}_{4}(2 \theta=31.2,36.8,44.5,59.3$ and $65.1^{\circ}$ ) existed. The existence of both cobalt and the oxide phase might reflect the catalyst state under reaction conditions. On the other hand, since the sample was cooled in a methane/oxygen mixture to room 


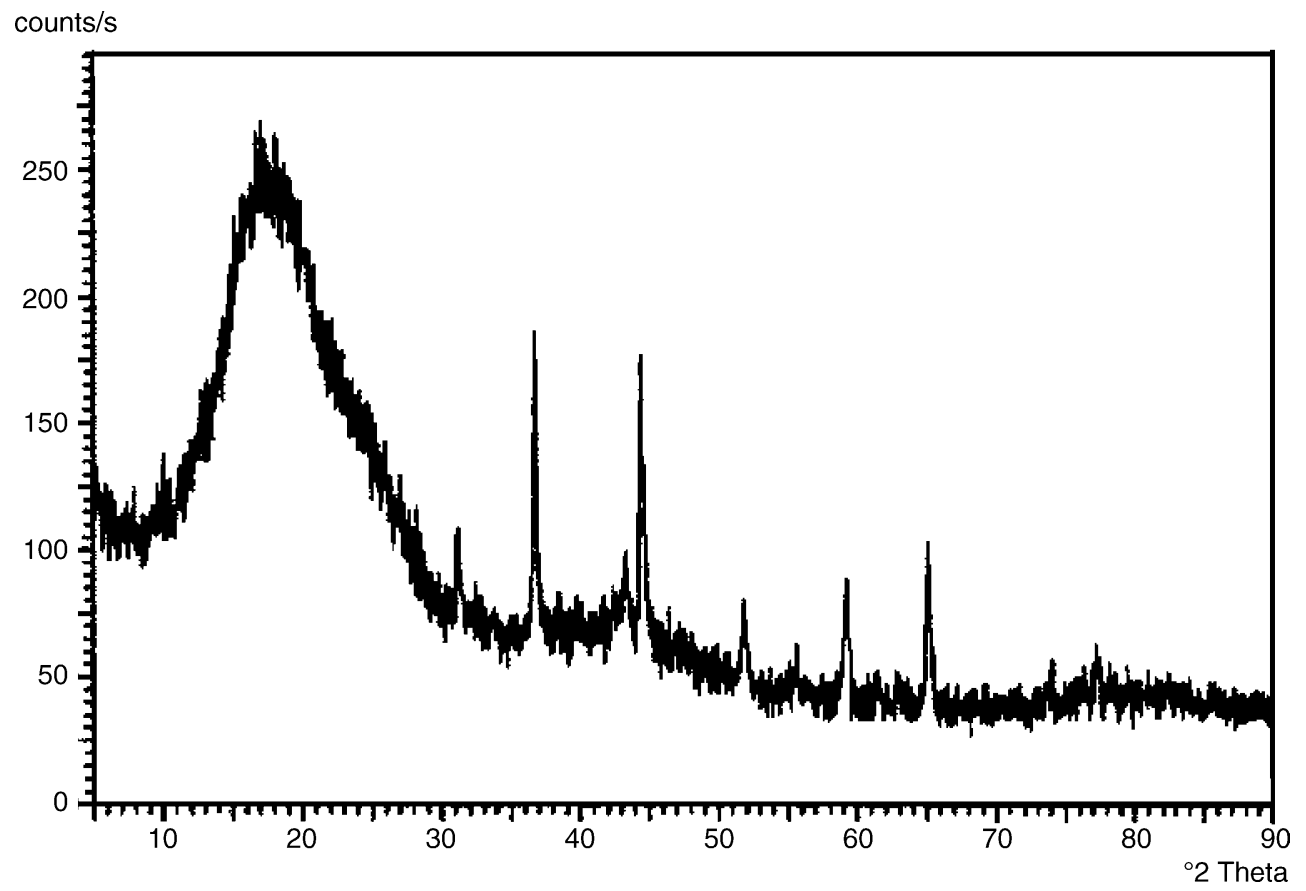

Fig. 1. X-ray diffraction pattern of cobalt foil after undergoing reaction.

temperature before being analysed, some oxide might be formed in that stage.

From the SEM photographs of the surfaces of both the cobalt wire and foil after undergoing reaction, it was observed that the top layer of the cobalt wire was "peeled off", as shown in Fig. 2, exposing the lower layer. Rough surfaces on both wire and foil were also observed, clearly indicating the occurrence of surface

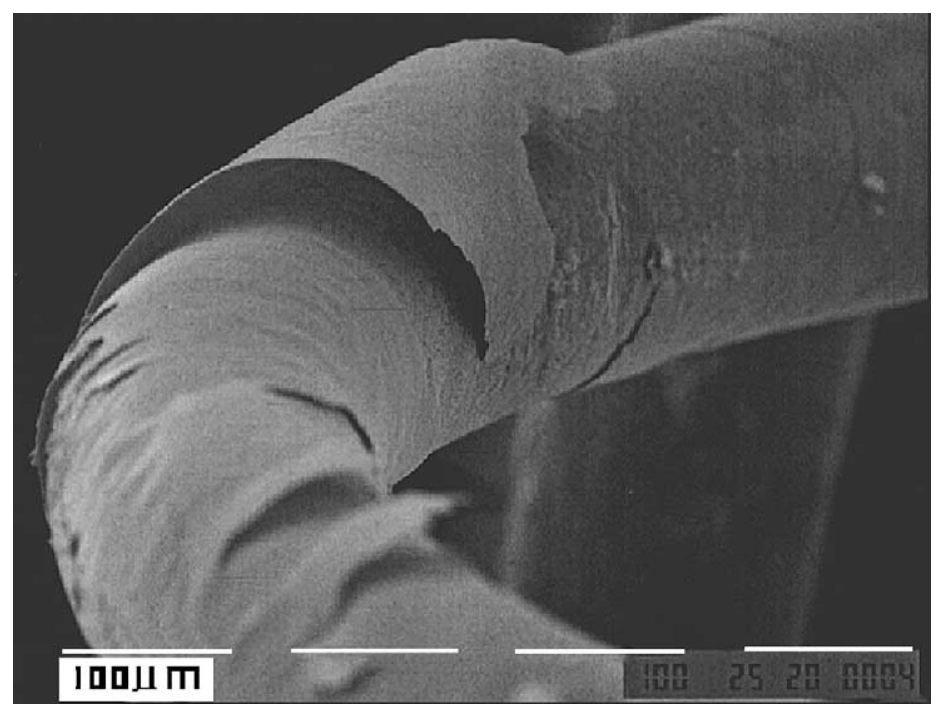

Fig. 2. SEM micrograph of cobalt wire after undergoing reaction. 


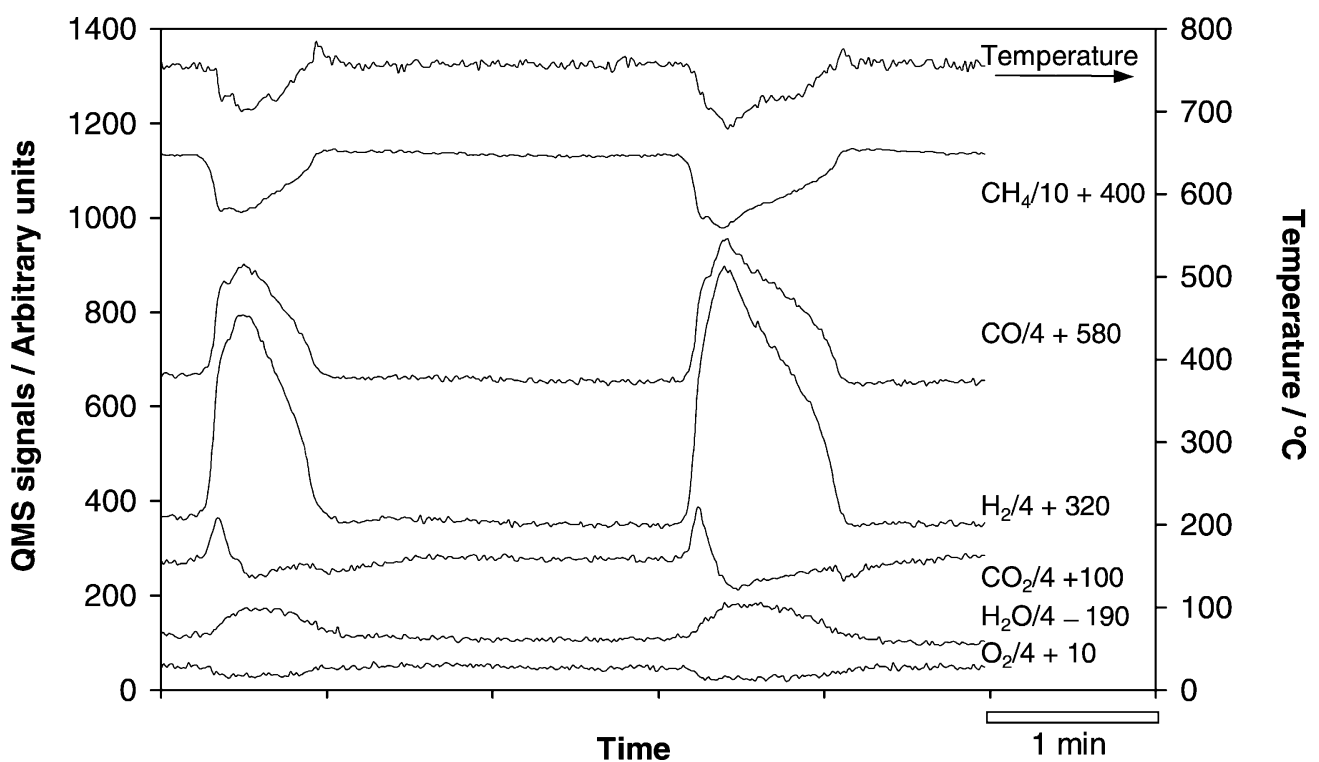

Fig. 3. Oscillations over cobalt foil in the temperature range of $700-784{ }^{\circ} \mathrm{C}$, with methane/oxygen ratio $=5: 1$.

reconstruction during the reaction, probably by many cycles of oxidation and reduction.

\subsection{General observation on the oscillation of methane oxidation over cobalt foil and wire}

The typical oscillation patterns displayed during the oxidation of methane for both the cobalt foil and wire at low and high temperature are depicted in Figs. 3-6. It should be noted that the QMS signal of both the reactants and products illustrated in the figures have been vertically offset by the factors shown in the figures. Oscillations were generally observed at temperatures in the range of $700-870{ }^{\circ} \mathrm{C}$ and for gas mixtures with methane/oxygen ratios ranging from 2:1 to 29:1. In general, after the oxidation reaction started, it was observed that an induction period of between 1 and 2 min was required before oscillations commenced. This induction period was found to be dependent on the temperature and as the temperature was increased, the induction period was found to decrease. Subsequently, the stable and repeatable oscillations became established 5-10 $\mathrm{min}$ after the induction period was seen. Although this effect featured more prominently and frequently in the runs over cobalt foil, it was also present with runs over cobalt wire but was not so obvious.

The main reaction producing the oscillations appeared to be the partial oxidation of methane to carbon monoxide and hydrogen. Carbon dioxide was also produced, together with some water. It can be seen that the oscillations increase as the temperature was raised, showing that the reaction causing the oscillations was active. The temperature also oscillated, with the minimum temperature always corresponding to a peak in $\mathrm{CO}$ and $\mathrm{H}_{2}$ production. It has been found that the minimum temperature was always below the temperature attained by the sample in the absence of reaction, indicating that an endothermic reaction was occurring.

Various oscillatory waveforms were observed, such as simple sharp peaks, single peaks with shoulders, double peaks and multiple peaks. All oscillations ceased when the temperature exceeded $900^{\circ} \mathrm{C}$ or the methane/oxygen gas ratio was reduced to $1: 1$. Hysteresis in the activity was also observed during methane oxidation as the reaction temperature was cycled up and down. Although very few studies on hysteresis activity have been conducted on cobalt catalysts, the hysteresis behaviour during methane oxidation over palladium catalyst has been widely studied [13] 


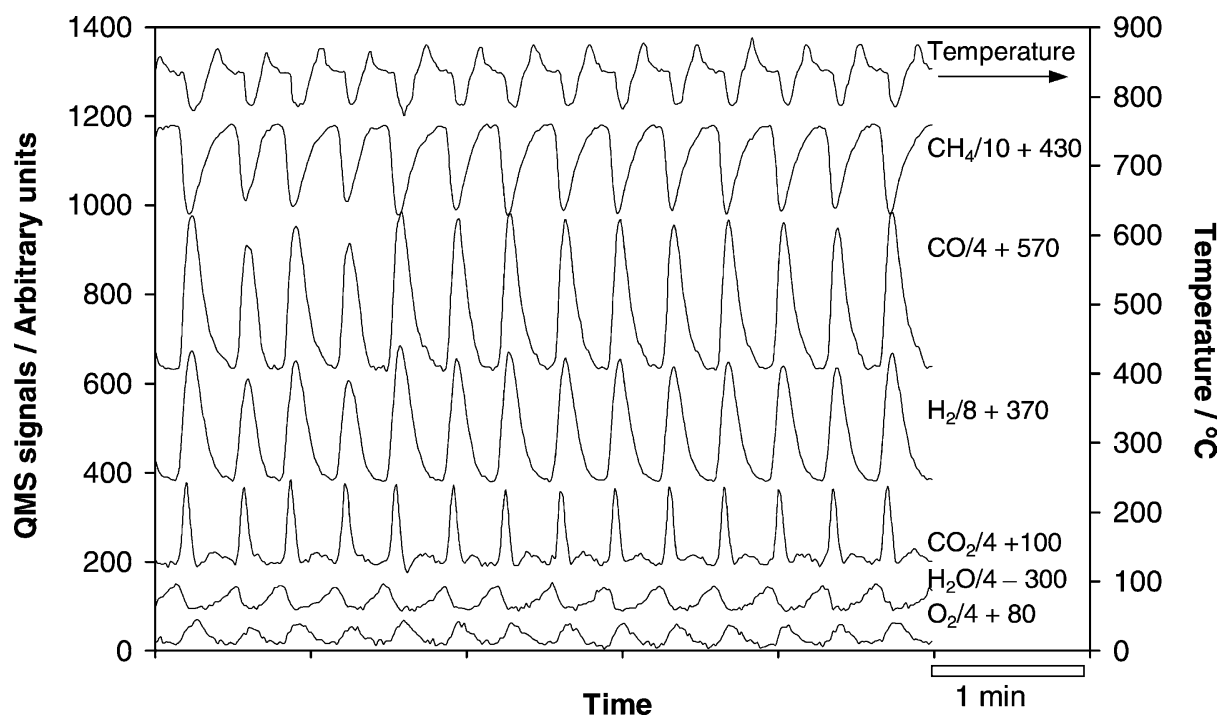

Fig. 4. Oscillations over cobalt foil in the temperature range of $785-869^{\circ} \mathrm{C}$, with methane/oxygen ratio $=5: 1$.

These oscillations can be distinguished from those occurring on the chromel-alumel thermocouple wires because they generally occurred in a higher temperature range and the change in temperature during oscillations was much greater. The unsheathed thermocouple wires produced oscillations at around $700^{\circ} \mathrm{C}$ with a temperature change of only $7-8^{\circ} \mathrm{C}$ [11]. In the experiments described here, the thermocouple wires were sheathed to within a few millimetres of the junction of the cobalt wire or foil and access to reaction gases was therefore greatly restricted. The surface area of the cobalt wire or foil was also much greater than that of the thermocouple wires.

It has been observed that the main $\mathrm{CO}, \mathrm{CO}_{2}$ and $\mathrm{H}_{2}$ peaks are accompanied by a fall in temperature, showing that the overall process is endothermic. This

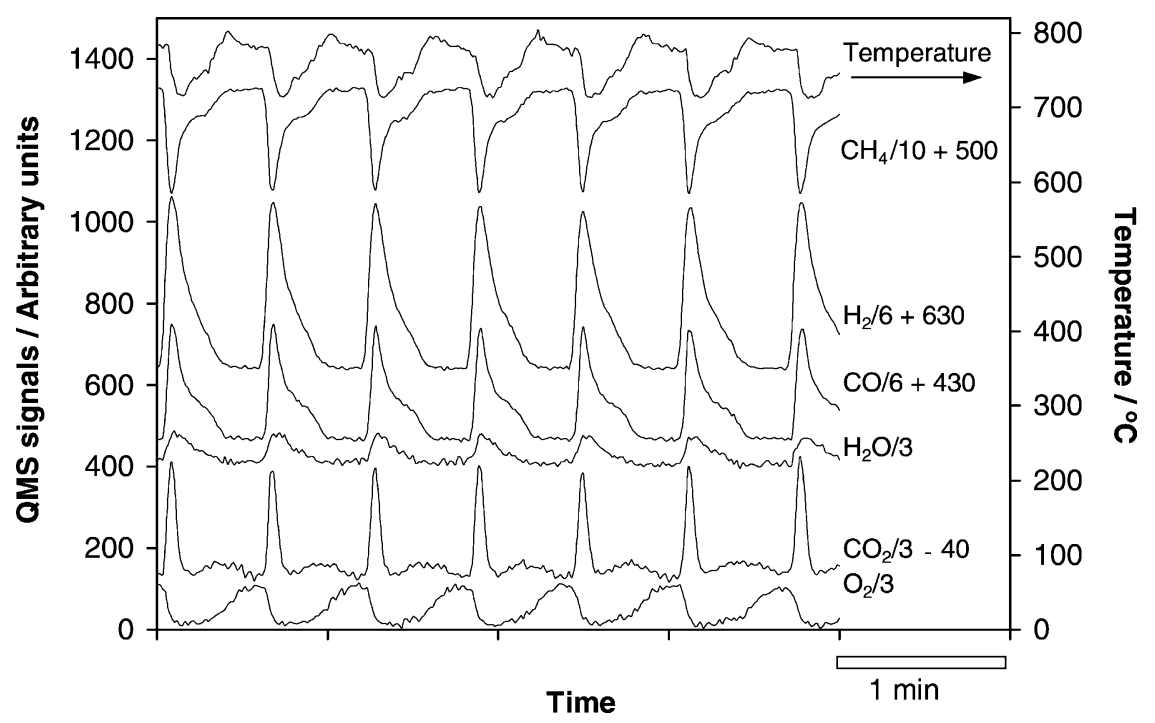

Fig. 5. Oscillations over cobalt wire in the temperature range of $718-870^{\circ} \mathrm{C}$, with methane/oxygen ratio $=5: 1$. 


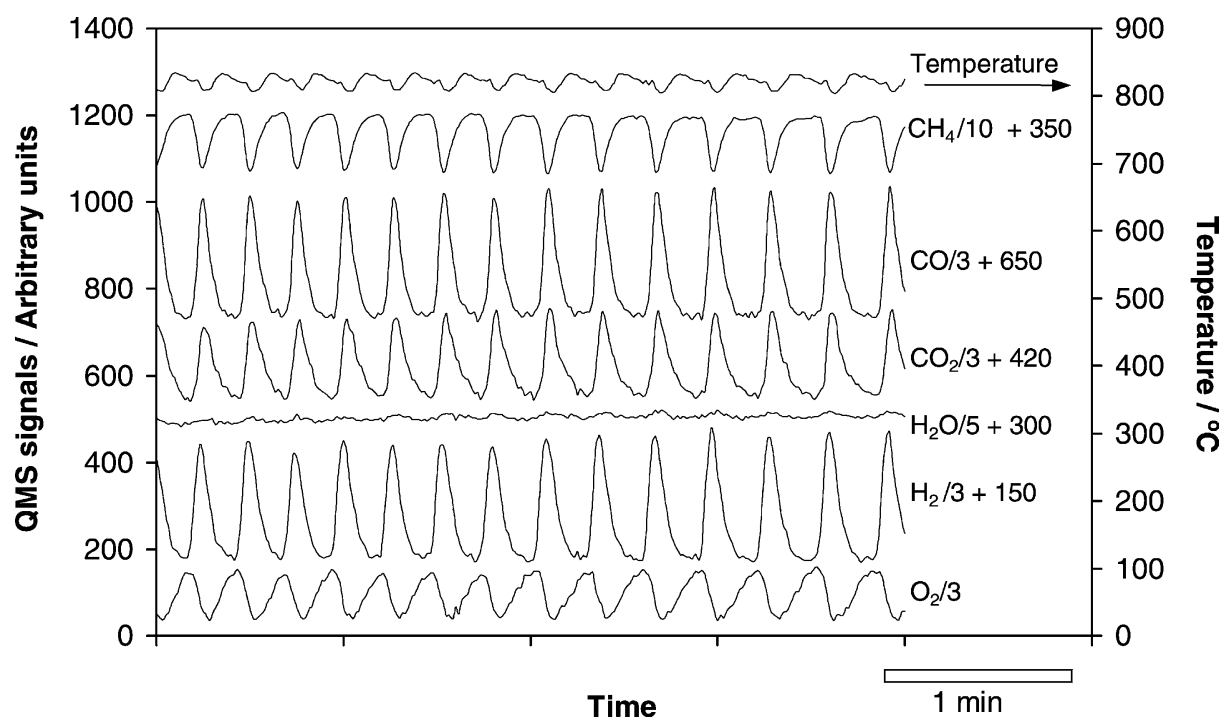

Fig. 6. Oscillations over cobalt wire in the temperature range of $809-834{ }^{\circ} \mathrm{C}$, with methane/oxygen ratio $=5: 1$.

presents a problem because the oxidation reactions of methane to $\mathrm{CO}$ and $\mathrm{CO}_{2}$ are both exothermic:

$$
\begin{aligned}
& \mathrm{CH}_{4}(\mathrm{~g})+\frac{1}{2} \mathrm{O}_{2}(\mathrm{~g}) \rightarrow \mathrm{CO}(\mathrm{g})+2 \mathrm{H}_{2}(\mathrm{~g}), \\
& \Delta \mathrm{H}_{298 \mathrm{~K}}=-36.1 \mathrm{~kJ} \mathrm{~mol}^{-1} \\
& \mathrm{CH}_{4}(\mathrm{~g})+2 \mathrm{O}_{2}(\mathrm{~g}) \rightarrow \mathrm{CO}_{2}(\mathrm{~g})+2 \mathrm{H}_{2} \mathrm{O}(\mathrm{g}), \\
& \Delta H_{298 \mathrm{~K}}=-802.7 \mathrm{~kJ} \mathrm{~mol}^{-1}
\end{aligned}
$$

Although the reforming reactions:

$$
\begin{aligned}
& \mathrm{CH}_{4}(\mathrm{~g})+\mathrm{CO}_{2}(\mathrm{~g}) \rightarrow 2 \mathrm{CO}(\mathrm{g})+2 \mathrm{H}_{2}(\mathrm{~g}) \\
& \Delta \mathrm{H}_{298 \mathrm{~K}}=246.9 \mathrm{~kJ} \mathrm{~mol}^{-1} \\
& \mathrm{CH}_{4}(\mathrm{~g})+\mathrm{H}_{2} \mathrm{O}(\mathrm{g}) \rightarrow \mathrm{CO}(\mathrm{g})+2 \mathrm{H}_{2}(\mathrm{~g}) \\
& \Delta H_{298 \mathrm{~K}}=225.7 \mathrm{~kJ} \mathrm{~mol}^{-1}
\end{aligned}
$$

produce $\mathrm{CO}$ and $\mathrm{H}_{2}$ and are both endothermic, they cannot explain the temperature drop because they are secondary reactions which rely on the highly exothermic production of $\mathrm{CO}_{2}$ and $\mathrm{H}_{2} \mathrm{O}$ before they can occur.

For an endothermic reaction to occur, it is necessary for at least some of the oxygen to be provided by surface oxide. Bulk $\mathrm{CoO}$ has a heat of formation of $-237.9 \mathrm{~kJ} \mathrm{~mol}^{-1}$ at $298 \mathrm{~K}$ and the participation of this oxide in the reaction would be more than sufficient to make the overall reaction endothermic. The overall reaction can then be represented as

$$
\mathrm{CH}_{4}(\mathrm{~g})+\mathrm{CoO}(\mathrm{s}) \rightarrow \mathrm{Co}(\mathrm{s})+\mathrm{CO}(\mathrm{g})+2 \mathrm{H}_{2}(\mathrm{~g})
$$

By using the value of $-155.6 \mathrm{~kJ} \mathrm{~mol}^{-1}$ for the free energy of formation of cobalt oxide at $1000 \mathrm{~K}$ which was calculated from a formula given by Gurvitch et al. [14], the free energy of reaction (5) was calculated to be $-64.1 \mathrm{~kJ} \mathrm{~mol}^{-1}$ at $1000 \mathrm{~K}$, so it can be seen that the equilibrium will still favour the gaseous products.

It follows from this discussion that a large amount of the oxygen required to produce the $\mathrm{CO}$ and $\mathrm{CO}_{2}$ that appears in the peaks must come from the reduction of cobalt oxide. This reduction was confirmed from the analysis of Figs. 7 and 8, where the methane/oxygen ratio was kept at 29:1 and 9:1, respectively. It can be seen that the oxygen signal was always close to zero, showing that virtually all of the oxygen was used up in the reaction. Thus, the rate of oxygen uptake remained constant even though the production of oxygen containing products fluctuated wildly. This observation can only be explained if the oxygen was alternatively stored and then released from the surface. On this basis, the sharp peaks can be associated with the rapid reduction of cobalt oxide and the long tail that follows with the re-oxidation of the surface. 


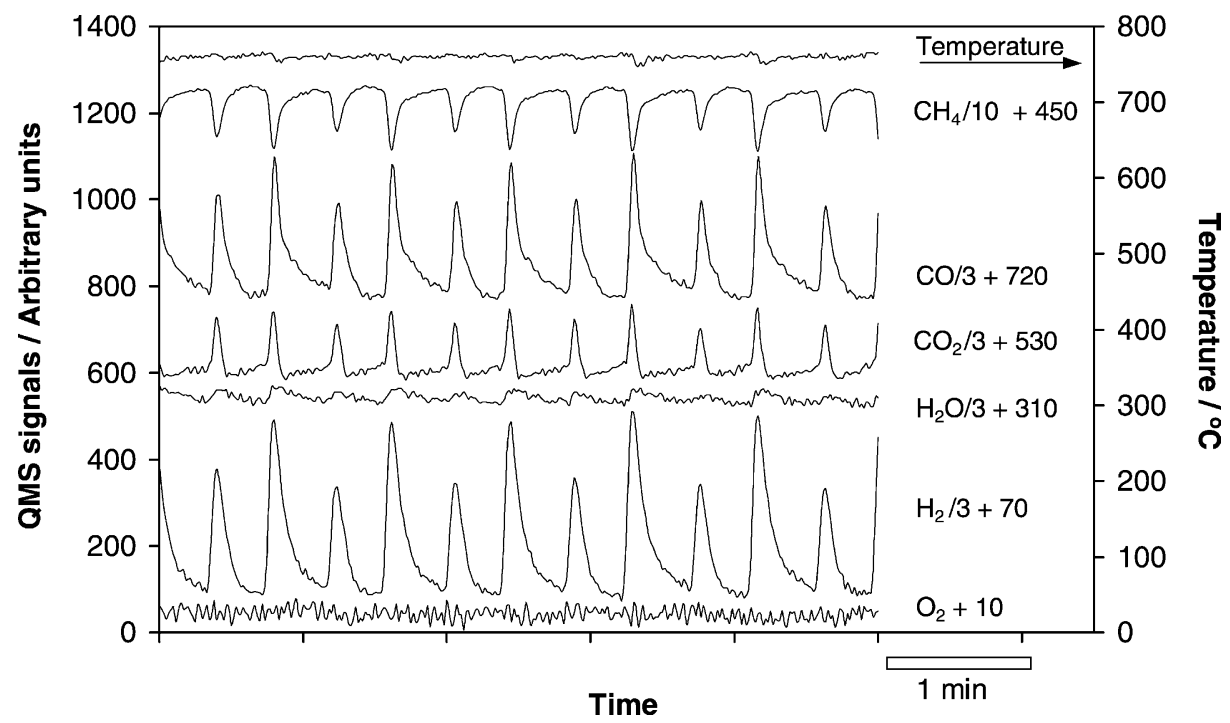

Fig. 7. Oscillations over cobalt wire in the temperature range of $750-765^{\circ} \mathrm{C}$, with methane/oxygen ratio $=29: 1$.

\subsection{Effects of varying feed gas methane/oxygen ratio}

\subsubsection{Effects on oscillatory behaviour over cobalt wire}

Tables 1-3 summarise the changes in oscillations induced by varying the methane/oxygen ratio over cobalt wire, showing how the peak heights, base level signals, period of oscillation and the temperature drop are affected in the temperature range of $720-810^{\circ} \mathrm{C}$. The values in Table 1 show the peak heights of the gases, so the negative numbers mean the signal drops for the reactants whilst the positive numbers show the increase in the product signals. By analysis of the

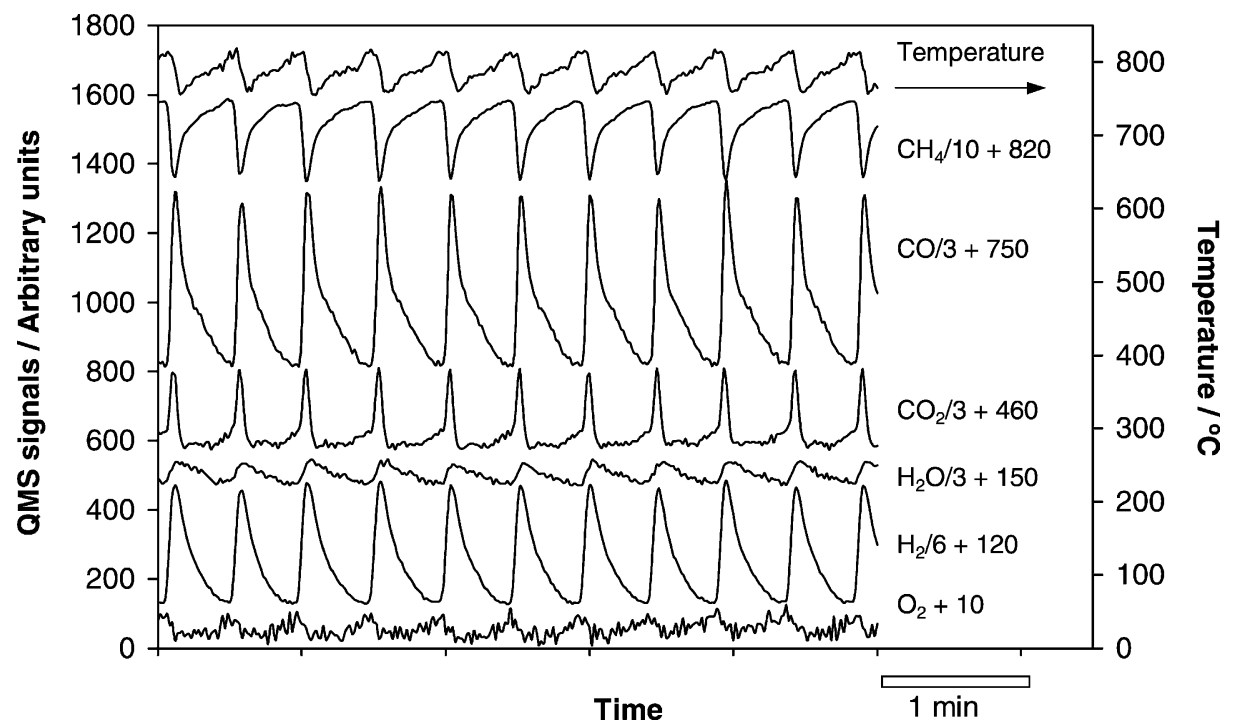

Fig. 8. Oscillations over cobalt wire in the temperature range of $738-786^{\circ} \mathrm{C}$, with methane/oxygen ratio $=9: 1$. 
Table 1

The effect of methane/oxygen ratio on the magnitude of the oscillations recorded by the mass spectrometer

\begin{tabular}{lccrrr}
\hline Gas & \multicolumn{2}{l}{$\begin{array}{l}\text { QMS peak heights at the specified methane/oxygen } \\
\text { ratio (arbitrary units) }\end{array}$} \\
\cline { 2 - 6 } & $29: 1$ & $14: 1$ & $9: 1$ & $4: 1$ & $2: 1$ \\
\hline $\mathrm{CO}$ & $918 / 600$ & $1376 / 1014$ & 1411 & 1764 & 1341 \\
$\mathrm{CO}_{2}$ & $459 / 328$ & $600 / 529$ & 670 & 635 & 1059 \\
$\mathrm{H}_{2}$ & $1164 / 705$ & $1764 / 1340$ & 1976 & 2506 & 1482 \\
$\mathrm{H}_{2} \mathrm{O}$ & $88 / 59$ & $159 / 123$ & 159 & 247 & 212 \\
$\mathrm{O}_{2}$ & 0 & -23 & -47 & -176 & -176 \\
$\mathrm{CH}_{4}$ & $-1412 /-982$ & $-2000 /-1576$ & -2117 & -2588 & -2000 \\
\hline
\end{tabular}

Table 2

The effect of methane/oxygen ratio on the base level of the QMS signals recorded by the mass spectrometer

\begin{tabular}{lrrrrr}
\hline Gas & \multicolumn{5}{c}{$\begin{array}{l}\text { Base level of QMS signals at the specified } \\
\text { methane/oxygen ratio (arbitrary units) }\end{array}$} \\
\cline { 2 - 6 } & $29: 1$ & $14: 1$ & $9: 1$ & $4: 1$ & $2: 1$ \\
\hline $\mathrm{CO}$ & 168 & 184 & 214 & 300 & 318 \\
$\mathrm{CO}_{2}$ & 203 & 293 & 394 & 685 & 476 \\
$\mathrm{H}_{2}$ & 70 & 71 & 71 & 71 & 71 \\
$\mathrm{H}_{2} \mathrm{O}$ & 646 & 833 & 981 & 1306 & 854 \\
$\mathrm{O}_{2}$ & 37 & 37 & 46 & 71 & 1164 \\
$\mathrm{CH}_{4}$ & 8000 & 7823 & 7641 & 7150 & 6882 \\
\hline
\end{tabular}

results shown in the tables the following points can be made.

(a) Data shown in Tables 1 and 2 indicated that two types of reaction appeared to be occurring: reaction (1) producing mainly $\mathrm{CO}+\mathrm{H}_{2}$, and reaction (2) producing mainly $\mathrm{CO}_{2}+\mathrm{H}_{2} \mathrm{O}$. The first reaction was significantly oscillating which was seen in the large $\mathrm{CO}$ and $\mathrm{H}_{2}$ peaks. It was observed that the oscillation peaks steadily increased in size as the oxygen content in the gas was in-

Table 3

The effect of methane/oxygen ratio on the period of oscillation and the temperature drop recorded during oscillation

\begin{tabular}{lllllc}
\hline $\begin{array}{l}\text { Methane/oxygen } \\
\text { ratio }\end{array}$ & $29: 1$ & $14: 1$ & $9: 1$ & $4: 1$ & $2: 1$ \\
$\begin{array}{l}\text { Period of } \\
\quad \text { oscillations (s) }\end{array}$ & 27 and 22 & 31 and 27 & 27 & 38 & $\approx 300^{\mathrm{a}}$ \\
$\begin{array}{l}\text { Fall in } \\
\text { temperature (K) }\end{array}$ & 13 & 35 & 48 & 90 & 15 \\
\hline$\quad$ a Irregular. & & & & & \\
\hline
\end{tabular}

creased up to a methane/oxygen ratio of $4: 1$. The oscillation of the second reaction appeared to be less significant which can be seen from the figures in Table 1 showing that the $\mathrm{CO}_{2}$ peaks remained more or less constant as the methane/oxygen ratio was changed. The insignificance of oscillations becomes apparent when the base levels of $\mathrm{CO}_{2}$ and $\mathrm{H}_{2} \mathrm{O}$ are examined. Part of the QMS signal for these gases can be attributed to background gases in the mass spectrometer; however, there must also be considerable amount of reaction occurring because both signals more than doubled when the methane/oxygen ratio was changed form 29:1 to $4: 1$. There was also a marked rise in the $\mathrm{CO}$ base level. Significantly, the $\mathrm{H}_{2}$ base level remained close to zero, showing that no hydrogen was produced in the non-oscillating reaction.

Therefore, it is likely that the oscillating reaction is confined to only certain parts of the surface, for example, particular crystal planes where the oxide layer can be alternately reduced to the metal and then re-oxidised. Since $\mathrm{CO}_{2}$ and $\mathrm{H}_{2} \mathrm{O}$ are mainly produced by the non-oscillating reaction, it is most likely that this reaction is occurring over an oxide layer that does not undergo complete reduction to the metal.

(b) The maximum quantity of products obtained was found to occur at a methane/oxygen ratio of $4: 1$ for both the $\mathrm{CO}+\mathrm{H}_{2}$ oscillating reaction and the $\mathrm{CO}_{2}+\mathrm{H}_{2} \mathrm{O}$ non-oscillating reaction. The rate of reaction decreases when more oxygen than this is present, i.e. methane/oxygen ratio $<4: 1$, possibly because of the competition between methane and oxygen for suitable sites. However, there is one exception to this rule in that the $\mathrm{CO}_{2}$ oscillating component was observed to increase in going from a $4: 1$ to a $2: 1$ methane/oxygen ratio.

(c) The oscillations take on a bi-modal character at methane/oxygen ratios of 29:1 and 14:1, with alternate strong and weak oscillations. The period between the oscillations was also bi-modal with the period prior to a weak oscillation being longer than that proceeding a strong oscillation. The reason for this behaviour is unclear.

(d) It was observed that, in an oscillation cycle, there were typically a temperature rise and a temperature drop. That temperature drop was observed below the reactor temperature indicating the 
existence of endothermic reactions. It can be seen from Table 3 that the temperature fall increased from 13 to 90 when the methane/oxygen ratio was changed from 29:1 to 4:1 indicating the increase in the contribution of the endothermic reaction in an oscillation cycle. The fall in temperature was not proportional to the size of the $\mathrm{CO}$ and $\mathrm{H}_{2}$ peaks. This disproportionality may arise because the $\mathrm{CO}_{2}$ peak, which represents an exothermic process, remained more or less constant as the oxygen content of the gas supply increase. Thus the relative contribution that made to the peak diminished at low methane/oxygen ratios and the effect from the endothermic reaction became more significant.

(e) At a 2:1 methane/oxygen ratio, it was observed that the period between the oscillations became somewhat erratic and this was also accompanied by a change in the shape of peaks. The $\mathrm{CO}, \mathrm{H}_{2}$ and $\mathrm{CO}_{2}$ peaks all had the same general shape whereas at higher ratios, there was a shoulder on the $\mathrm{CO}$ and $\mathrm{H}_{2}$ peaks and the $\mathrm{CO}_{2}$ peak was much narrower and reached its maximum before the other peaks. A complex temperature profile for the peak was also obtained. It consisted of a temperature fall sandwiched between two sharp rises in the temperature. This could readily be explained in terms of the relative contributions made by the exothermic production of $\mathrm{CO}_{2}$ and the endothermic production of $\mathrm{CO}$ and $\mathrm{H}_{2}$ from oxide. The $\mathrm{CO}_{2}$ peak was wider than the $\mathrm{CO}$ and $\mathrm{H}_{2}$ peaks, with the result that there was relatively more $\mathrm{CO}_{2}$ present at the start and end of an oscillation than there was in the middle. A common feature of the oscillations at all methane/oxygen ratios was that $\mathrm{CO}_{2}$ was the first product to start rising.

\subsubsection{Effects on oscillatory behaviour over cobalt foil}

Similar results were obtained with cobalt foil, with the same trends being observed when the methane/ oxygen ratio was changed. Bi-modal behaviour was also observed, although it was more extreme and occurred over the whole range of the methane/oxygen ratios, as shown in Figs. 9 and 10.

\subsection{Effects of varying temperature}

Oscillatory behaviour was only observed when the temperature exceeded $640^{\circ} \mathrm{C}$. Below this temperature, the oxidation of methane proceeded slowly and without oscillations. To study the effect of temperature on the oscillations, samples of cobalt wire and foil were slowly heated in a 5:1 methane/oxygen mixture.

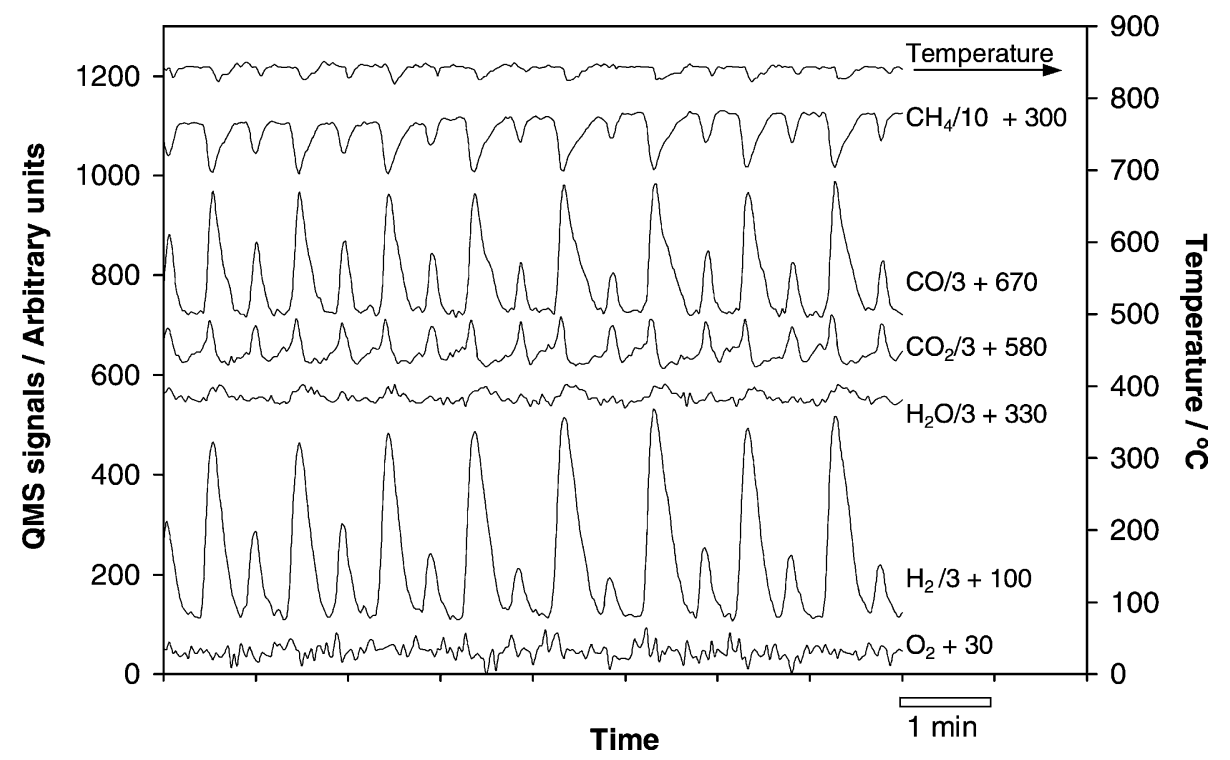

Fig. 9. Oscillations over cobalt foil in the temperature range of $823-850^{\circ} \mathrm{C}$, with methane/oxygen ratio $=29: 1$. 


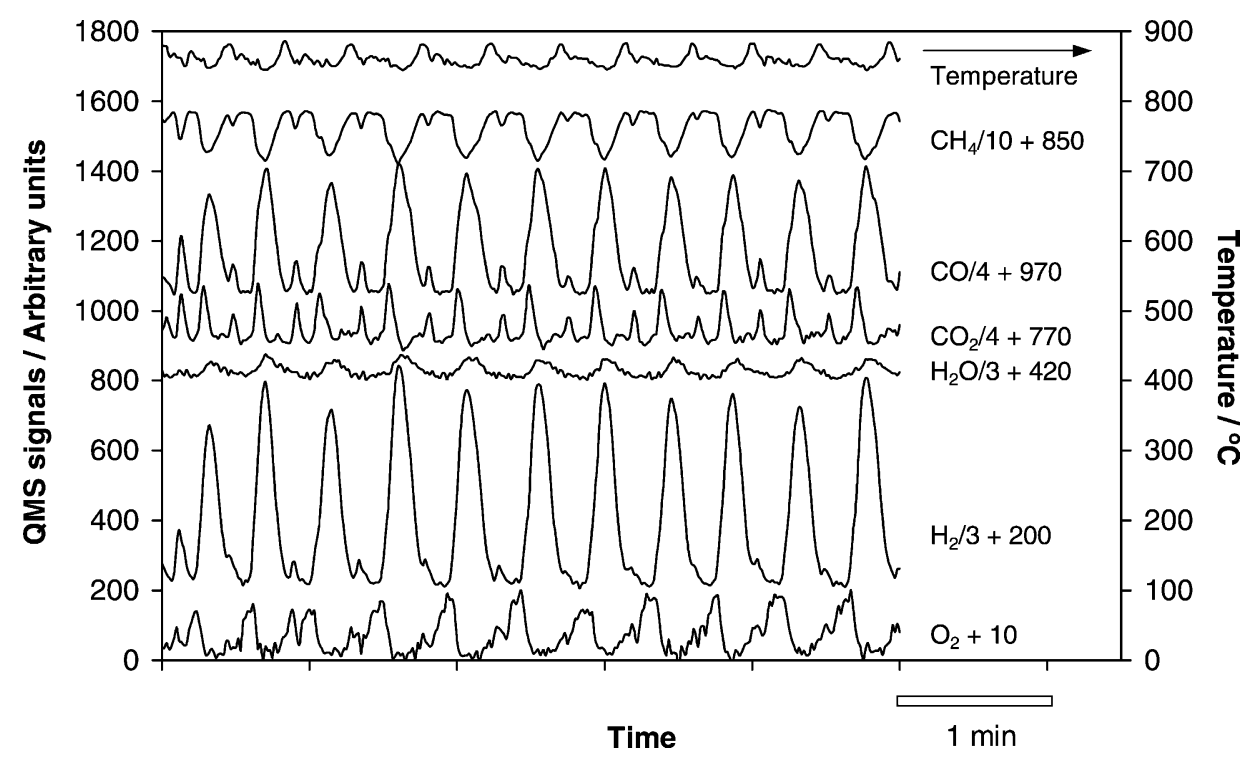

Fig. 10. Oscillations over cobalt foil in the temperature range of $845-886^{\circ} \mathrm{C}$, with methane/oxygen ratio $=5: 1$.

Typical results for the cobalt wire are shown in Figs. 3 and 4 where it can be seen that the frequency of the oscillations more than doubled as the temperature was raised from $718 / 807$ to $809 / 834^{\circ} \mathrm{C}$. Significant differences were also seen in the waveforms. At the lower set of temperatures, the $\mathrm{CO}$ and $\mathrm{H}_{2}$ peaks have pronounced shoulders whereas at the higher set of temperatures, they appeared as single peaks. Differences were also observed in the $\mathrm{CO}_{2}$ peaks, which were much narrower than the $\mathrm{CO}$ and $\mathrm{H}_{2}$ peaks in the low temperature range and reaches its maximum value before them. However, in the higher temperature range, the $\mathrm{CO}_{2}$ peaks were actually slightly broader than the other peaks and this resulted in the $\mathrm{CO}_{2}$ signal being somewhat greater than the $\mathrm{CO}$ signal towards the end of the peak. This observation was reflected in the temperature profile, which showed a temperature peak following the usual temperature minimum and this was thought to be caused by the exothermic production of $\mathrm{CO}_{2}$ dominating the endothermic $\mathrm{CO}$ reaction.

In general, the cobalt foil showed rather more complex results that the cobalt wire. Very weak, low frequency oscillations were seen at lower temperatures as depicted in Fig. 3. At higher temperatures, the oscillations showed features of both the low and high temperature oscillations observed with cobalt wire, as can be seen in Fig. 4. The $\mathrm{CO}$ and $\mathrm{H}_{2}$ peaks were single peaks without shoulders, similar to those observed with the wire at high temperature, but the $\mathrm{CO}_{2}$ peaks were much narrower and more like those observed with the wire at low temperature. An additional feature observed with the cobalt foil oscillations was that the $\mathrm{CO}_{2}$ signal showed a second, smaller peak midway between the large peaks.

Fig. 3 also gives a good example of the complex nature of the oscillation waveforms, in which three distinct stages to the redox cycle can be distinguished:

(a) A narrow $\mathrm{CO}_{2}$ peak was produced in the first stage which was accompanied by sharp rises in the $\mathrm{CO}$ and $\mathrm{H}_{2}$ signals and a fall in the $\mathrm{O}_{2}$ signal. An appreciable drop in temperature was also seen and this must, therefore, represent the start of the reduction process, when the areas of reduced metal were small with the surrounding oxide providing enough oxygen to produce $\mathrm{CO}_{2}$ as well as $\mathrm{CO}$.

(b) This first stage was followed by a maximum in the $\mathrm{CO}$ and $\mathrm{H}_{2}$ signals and a fall in the $\mathrm{CO}_{2}$ signal to a value below that at the start of the oscillation. The latter observation showed that there was a 
shortage of oxygen at this stage, an indication that most of the oxide layer had now been reduced and that a significant part of the reaction was now occurring over the metal. The marked upturn in the $\mathrm{CO}$ and $\mathrm{H}_{2}$ signals observed at this stage was probably brought about by the abrupt drop in the $\mathrm{CO}_{2}$ signal, releasing more oxygen for the $\mathrm{CO}+$ $\mathrm{H}_{2}$ reaction. The latter reforming reaction requires one quarter of the amount of oxygen needed for the total oxidation of methane to $\mathrm{CO}_{2}$ and $\mathrm{H}_{2} \mathrm{O}$.

(c) At the final stage of the oscillation, broad shoulders on the $\mathrm{CO}$ and $\mathrm{H}_{2}$ peaks were obtained. During this time, the $\mathrm{CO}_{2}$ signal began to rise, probably indicating that re-oxidation was beginning to occur. This final stage of the oscillation appeared to correspond to the reaction occurring over the metal on a decreasing amount of surface as the oxide layer progressively builds up.

Although the temperature was always varying due to the oscillations, it was possible to measure the frequency of the oscillations as a function of the average temperature over a cycle. It was found that the plot of $\ln (t)$, where $t$ is the oscillation period, against the reciprocal of the absolute temperature $(T)$ gave a good straight line, as shown in Fig. 11 for cobalt wire and foil. The data for cobalt wire were taken when the temperature was slowly rising whereas the data for the cobalt foil were taken when the temperature was falling. We will assume that there is some reac- tion controlling the frequency of the oscillations with the rate constant which is proportional to $1 / t$. Thus, the activation energy for the process controlling the oscillations can be obtained from the equation:

$\frac{1}{t}=A \exp \left(-\frac{E_{\mathrm{a}}}{R T}\right)$

where $t$ is the period of the oscillation, $A$ is a constant and $E_{\mathrm{a}}$ the activation energy. The values obtained for the activation energies for cobalt wire and cobalt foil are $150 \pm 20$ and $126 \pm 18 \mathrm{~kJ} \mathrm{~mol}^{-1}$, respectively. Due to the way in which the data had to be obtained, the error limits of these values are large. It was also not clear if the value obtained when the temperature was rising was significantly greater than the value obtained when the temperature was falling. Since there is known to be hysteresis in the system, it would not be surprising for a difference to be obtained between the two activation energies.

\subsection{Effects of cutting off methane or oxygen gas supply temporarily}

\subsubsection{Cutting methane supply off temporarily}

With both the cobalt foil and wire, the oscillations of the all reaction products were observed to cease when the methane was turned off to temporarily stop the reaction. The oxygen signal gradually rose and there was a drop in the temperature of about $30^{\circ} \mathrm{C}$ to a value found previously when no reaction was

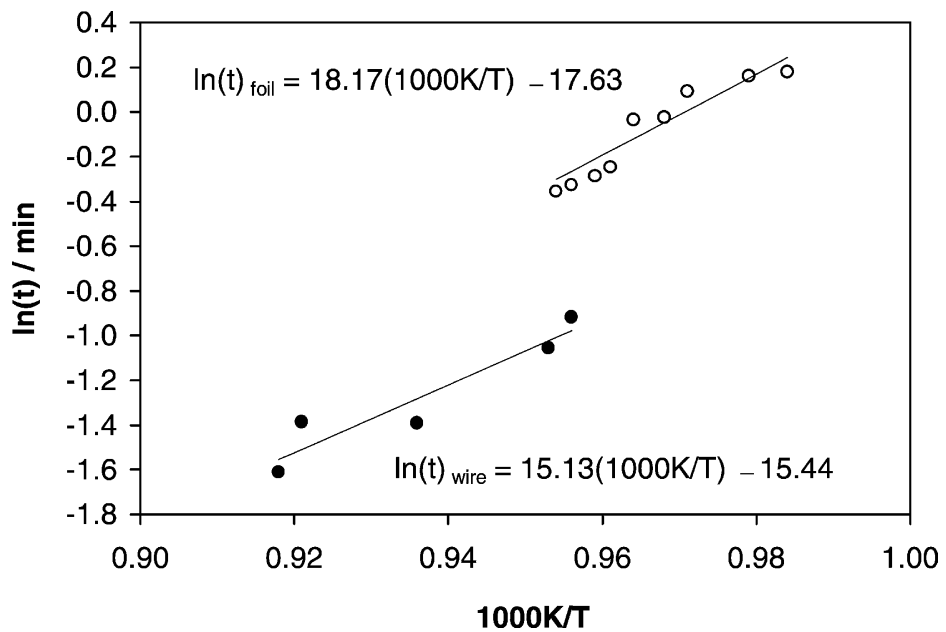

Fig. 11. Plot of $\ln (t)$ vs. $1000 \mathrm{~K} / T$ for cobalt wire (filled circles) and cobalt foil (open circles). 


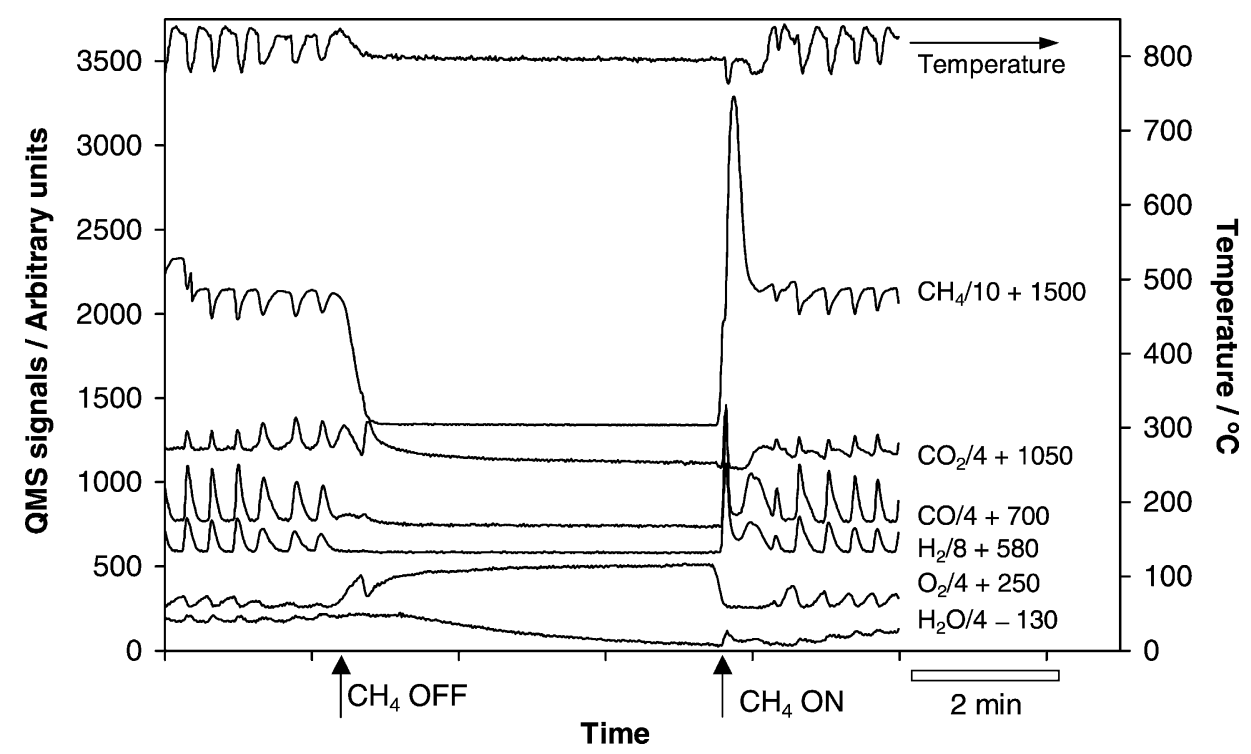

Fig. 12. Effects of turning the methane supply off and on. Methane was switched off and on again with the methane/oxygen ratio after switch on $=5: 1$, in the temperature range of $779-834^{\circ} \mathrm{C}$.

occurring (see Fig. 12). When the methane supply was restored, there was an almost instantaneous evolution of $\mathrm{CO}, \mathrm{H}_{2}, \mathrm{CO}_{2}$ and $\mathrm{H}_{2} \mathrm{O}$ which gave very sharp peaks with a magnitude much greater than that obtained in the normal oscillations observed with a constant as flux. This was accompanied by a fall in temperature measured when reaction was occurring, the overall process must therefore be endothermic. This result is an indication that the oxide layer was being reduced to the metal. Hence, the oxide layer must be quite thick to be able to produce such a large quantity of $\mathrm{CO}$ and $\mathrm{CO}_{2}$.

A second, broader pulse of gas was also observed to occur about $30 \mathrm{~s}$ after the methane was restored. This consisted mainly $\mathrm{CO}, \mathrm{H}_{2}$ and $\mathrm{H}_{2} \mathrm{O}$, and was associated with a smaller, more gradual temperature drop of about $21{ }^{\circ} \mathrm{C}$. This was assumed to be a second reduction-oxidation cycle that produced larger peaks than normal because the system had not yet settled down after the prolonged exposure to oxygen.

\subsubsection{Cutting oxygen supply off temporarily}

When the oxygen supply was turned off, there was a final oscillation with larger $\mathrm{CO}$ and $\mathrm{H}_{2}$ peaks than usual and a smaller $\mathrm{CO}_{2}$ peak. All oscillations ceased after this. The results seemed to indicate that the oxy- gen was competing with methane for adsorption sites and that excess oxygen could have an inhibitory effect on the partial oxidation of methane.

Illustrated in Fig. 13 are the results obtained when the oxygen supply was restored over a cobalt foil with a 5:1 methane/oxygen gas mixture. Similar results were also obtained with cobalt wires. An initial surge of oxygen was observed in the figure due to the sudden opening of the oxygen supply line and this accompanied by intense $\mathrm{CO}$ and $\mathrm{CO}_{2}$ peaks and a large rise in the reaction temperature. More significantly, hardly any $\mathrm{H}_{2}$ or $\mathrm{H}_{2} \mathrm{O}$ were produced, showing that the oxidation of methane was not responsible for the $\mathrm{CO}$ and $\mathrm{CO}_{2}$ peaks. The process occurring was believed to be the oxidation of carbon, deposited on the surface during the period when only methane was present in the gas phase. This deposition could be significant in the absence of oxygen although carbon deposition could take place also in the presence of both reactants in the feed which was often observed during the partial oxidation of methane over other cobalt catalysts $[15,16]$. The large drop in the methane signal can be explained in terms of the displacement of methane in the flow line by the sudden surge of oxygen and the large pulse of $\mathrm{CO}$ and $\mathrm{CO}_{2}$, and does not necessarily mean that methane is consumed during the reaction. 


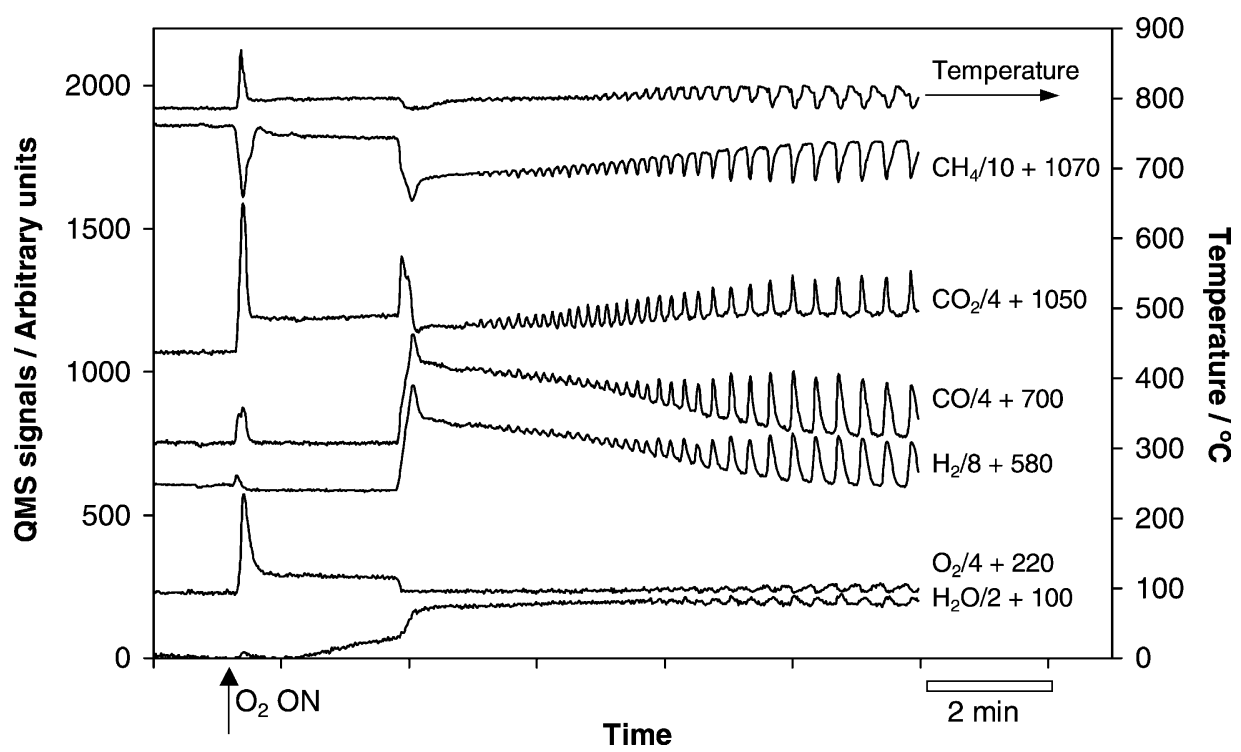

Fig. 13. Effects of turning the oxygen supply off and on. Oxygen supply was switched on with the methane/oxygen ratio after switch on $=5: 1$, in the temperature range of $785-869^{\circ} \mathrm{C}$.

Following this process, there was a period of just less than 2 min when oxidation of the cobalt surface appeared to be occurring. Evidence for this conclusion comes from the low oxygen signal detected, which should be about 1200 units on the arbitrary scale if there was no reaction occurring. During this period, the $\mathrm{CO}_{2}$ and $\mathrm{H}_{2} \mathrm{O}$ signals started to rise, and this could be an indication that full oxidation of methane to $\mathrm{CO}_{2}$ and $\mathrm{H}_{2} \mathrm{O}$ was beginning to occur over the oxide surface.

A sudden evolution of $\mathrm{CO}, \mathrm{CO}_{2}, \mathrm{H}_{2}$ and $\mathrm{H}_{2} \mathrm{O}$ was observed at the end of this period, which was accompanied by a $37^{\circ} \mathrm{C}$ fall in temperature. On the basis of the previous discussion, this must be an indication that the oxide surface had been reduced to the metal surface. It can also be deduced from the shapes of the $\mathrm{CO}$ and $\mathrm{CO}_{2}$ peaks that this reduction reaction occurs in two stages. It is not clear what process triggered the reduction; it could be that the oxide layer had reached a limiting thickness above which spontaneous re-crystallisation occurred, or that the reduction was initiated by the formation of metal nuclei above a certain critical size. A similar phenomenon was also observed with palladium where, after methane was introduced, an induction period was seen before and $\mathrm{CO}_{2}$ and $\mathrm{H}_{2} \mathrm{O}$ were formed. Su et al. [17] have at- tributed this phenomenon to the formation of metallic nuclei of palladium.

Following the initial surge in the $\mathrm{CO}, \mathrm{CO}_{2}$ and $\mathrm{H}_{2}$ signals, the $\mathrm{CO}_{2}$ signal dropped below its starting value but the $\mathrm{CO}$ and $\mathrm{H}_{2}$ signals remained high and started to oscillate. This showed that most of the surface remained in the metallic state, where $\mathrm{CO}$ and $\mathrm{H}_{2}$ were the main products of the methane/oxygen reaction. The oscillations slowly increased in magnitude until the variation in each signal extended from its base level (the value before the oscillations commenced) to a value close to that observed just after the first pulse. The increasing magnitude of the oscillations can be explained if the redox cycle, which was believed to be responsible for the oscillations, began on a small part of the surface and then slowly extended to cover the whole surface. The reason why this should happen is not clear and more research is needed to gain better understanding of this reaction behaviour.

\section{Conclusions}

Although oscillatory behaviour during methane oxidation has been frequently studied over palladium and nickel catalysts, studies involving cobalt catalyst have 
not been reported previously. Studies on the oscillatory behaviour were carried out under various reaction temperatures and methane/oxygen gas ratios. The catalyst was also analysed using two different analysis techniques after undergoing reaction: scanning electron microscopy and X-ray powder diffraction methods. Analysis of the SEM photographs revealed the presence of two layers, whereby the top layer was observed to be "peeled off" exposing the low layer. Both layers appeared rough and porous. With the XRD technique, the diffraction patterns obtained showed the presence of an oxide layer on the catalyst surface. The results of both these surface techniques reflected the hysteresis phenomena, observed in the catalytic activity of the reaction as the temperature was cycled up and down. The results obtained from the experimental studies indicate that the oscillatory behaviour exhibited during methane oxidation was related to the behaviour of the catalyst surface switching back and forth from the reduced state to the oxidised state. The reduction of the oxide layer followed by the almost immediate re-oxidation of the metal can be accounted for only if the oxide layer formed by oxidation is different from the oxide layer existing during reduction. Clearly, further research using a variety of surface science techniques is required before the detailed mechanism of this reaction can be elucidated.

\section{References}

[1] J.R. Rostrup-Nielsen, in: J.R. Anderson, M. Boudart (Eds.), Catalysis, Science and Technology, vol. 5, Springer, Berlin, 1984 (Chapter 1).

[2] D.L. Trimm, Catal. Rev. Sci. Eng. 16 (1977) 155.

[3] D. Konig, W.H. Weber, B.D. Poindexter, J.R. McBride, G.W. Graham, K. Otto, Catal. Lett. 29 (1994) 329.

[4] Y.Q. Deng, T.G. Nevell, Faraday Discuss. 105 (1996) 33.

[5] U.S. Ozkan, M.W. Kumthekar, G. Karakas, J. Catal. 171 (1997) 67.

[6] Y.Q. Deng, T.G. Nevell, J. Mol. Catal. A 142 (1999) 51.

[7] Y.H. Hu, E. Ruckenstein, Ind. Eng. Chem. Res. 37 (1998) 2333.

[8] J.G. Cohn, Ind. Eng. Chem. Res. 38 (1999) 1740.

[9] Y.H. Hu, E. Ruckenstein, Ind. Eng. Chem. Res. 38 (1999) 1742.

[10] Y.P. Tyulenin, M.Y. Sinev, V.V. Savkin, V.N. Korchak, Y.B. Yan, Kinet. Catal. 40 (1999) 404.

[11] X. Zhang, D.M.P. Mingos, D.O. Hayward, Catal. Lett. 72 (2001) 147.

[12] L.F. Adams, Engineering Measurements and Instrumentation, The English Universities Press, London, 1975, p. 368.

[13] P. Salomonsson, S. Johansson, B. Kasemo, Catal. Lett. 33 (1995) 1.

[14] L.V. Gurvitch, V. Veyts, C.B. Alcock, Thermodynamic Properties of Individual Substances, vol. 1, 4th ed., Hemisphere, New York, 1989.

[15] S. Tang, J. Lin, K.L. Tan, Catal. Lett. 59 (1999) 129.

[16] Y. Zhang, K.J. Smith, Catal. Today 77 (2002) 257.

[17] S.C. Su, J.N. Cartens, A.T. Bell, J. Catal. 176 (1998) 125. 